\title{
Shared waters: from global principles to regional agreements
}

\author{
M. Souza \& L. Tatemoto \\ Department of International Relations, \\ Pontifical Catholic University of Minas Gerais, Brazil
}

\begin{abstract}
This study sets out to investigate internationally agreed-upon principles and guidelines for water resources governance and their implementation in regional agreements for transboundary river basins - specifically the case of the Mekong River Commission, and the Convention of the Protection and Use of Transboundary Watercourses and International Lakes. The analysis, based on the Institutionalist theory of International Relations, indicates that the States parties to the Mekong River Commission perceive greater benefits in the limitation of their interdependence, but these States need the Commission as a means of control and information on the ways other member nations explore river resources. As for UNECE Member States, the previous existence of several river basin agreements and regulations from other regional organizations acts as a facilitator for the adoption of the recommendations of the Convention. However, the countries that have the most significant water management problems have not ratified the Convention. In summary, we may say that international principles and guidelines are incorporated only when relevant or adaptable to local needs.

Keywords: water resources governance, transboundary river basins, river commission, convention on the protection and use of transboundary watercourses and international lakes.
\end{abstract}

\section{Introduction}

The challenges of freshwater governance have become increasingly global in scope since the 1970s. This is due to the growing knowledge about the transboundary risks of worsening hydrosphere conditions, unsustainable usage of water and inefficiency of water management practices. Moreover, the expansion 
of conflicts arising from prolonged inequalities affecting the access to water for essential uses contributes to the international debates on the subject. Several international conferences since 1977 have addressed the issue of freshwater resources in order to seek measures to remedy or control problems such as water pollution, sanitation and waterborne diseases, lack of access to water, conflicts over freshwater resources, and threats such as environmental disasters.

As a result of the international dialogue, many principles and guidelines for water resources governance have been agreed-upon by the international society. This paper sets out to investigate the application of such principles and guidelines in regional agreements, in order to understand their incorporation process as they relate to interests of the involved political actors. The 'Mekong River Commission', in the South East Asia, and the 'Convention on the Protection and Use of Transboundary Watercourses and International Lakes', among United Nations Economic Commission for Europe (UNECE) Member States, are the two chosen case studies.

\section{Water governance and international politics}

The international debate on certain aspects of water management is not a recent development. In Europe, for example, international commissions for the Rhine and Danube rivers were formed during the $19^{\text {th }}$ century to solve matters of navigation, pollution and flood control [1]. However, the concerns about ecosystem heath and a more holistic view of the relationship between man and the environment are quite recent. The first post-Stockholm international conference that marked the beginning of broader international discussions on water resources was the United Nations Water Conference, in Mar del Plata, 1977. From this date until 2001 there have been six main conferences on the subject: Global Consultation on Safe Water and Sanitation for the 1990's (New Delhi, 1990), UN Conference on Environment and Development (Rio de Janeiro, 1992), International Conference on Water and the Environment (Dublin, 1992), Water and Sustainable Development International Conference (Paris, 1998), 2nd World Water Forum (Hague, 2000), International Conference on Freshwater (Bonn, 2001). Thenceforth it is the understanding of the research that a greater involvement of less relevant actors and preponderance of the recommendations of environmental and social NGOs has effectively masked real political progresses resulting from the meetings.

Though there are contradictions in some of the recommendations that were generated in such conferences, it is possible to summarize the resulting principles and guidelines as a conjunction of the basic principle of providing secure access to water for all people, the Dublin Principles of 1992 (1. Fresh water is a finite and vulnerable resource, essential to sustain life, development and the environment; 2 . Water development and management should be based on a participatory approach, involving users, planners and policy-makers at all levels; 3. Women play a central part in the provision, management and safeguarding of water; 4 . Water has an economic value in all its competing uses and should be recognized as an economic good), and others related to those, such 
as the polluter-pays and equitable use principles, and the recommendation for integrated river basin management. The Dublin Conference may be considered the most important international conference on water resources governance, and the Dublin Principles have been exhaustively repeated in many following conferences and publications in the field, in apparent contradiction to the lack of effective national and international incorporation of such principles.

Water is a limited, essential and unevenly distributed natural resource. Although renewable, it is extremely sensitive to human misuse. According to Bernauer: 'To some extent, scarcity and uneven distribution of freshwater resources (...) are caused by natural hydrological cycles. In many instances, however, these problems also result from unsustainable human consumption of freshwater. Political science theory and market failure theories developed by economists suggest that the principal reason for unsustainable use of natural resources (...) is that certain incentive structures as well as political and institutional problems prevent riparian countries and their constituencies from collectively establishing and operating effective management systems for transboundary water courses' [2].

Although the arrangements for international river basin management may be guided by internationally accepted principles and guidelines, they tend to assume specific local features: in theory, the institutional design meets the needs and challenges that the sharing of water resources presents on a given situation [3]. In this sense, the discussion about international cooperation towards shared water resources management requires a preliminary theoretical analysis of the decision-making process related to common-pool resources (CPRs). According to Ostrom: "The decisions and actions of CPR appropriators to appropriate from and provide a CPR are those of broadly rational individuals who find themselves in complex and uncertain situations. An individual's choice of behavior in any particular situation will depend on how the individual learns about, views, and weights the benefits and costs of actions and their perceived linkage with outcomes' [3].

The most successful experiences of water resources management at the local level are the ones in which the parties themselves decide on the most appropriate institutional design to facilitate the resolution of dilemmas of collective action. Thus, parties can make credible commitments and conceive new rules and institutions to provide more efficient structure of incentives for cooperative action $[3,4]$ that may also be true for international cooperation. Although the devised rules make cooperation possible, there usually are no enforcement mechanisms. States observe the commitments because the gains generated by cooperation within the institutional arrangements exceed those of noncooperation. Such institutions offer, however, standards that allow parties to perceive, in the actions of other parties, their particular level of compliance with the same rules.

Several factors are relevant to determine the ability to cooperate, the rules of cooperation and the behavior of actors. Actors estimate costs and capabilities of committing to new rules of common-pool resource usage, and the likely benefits of the agreement, thus being the structure of incentives for cooperation. The 
institutional rules and incentives shape the behavior of actors. The results of the interaction are evaluated by the parties, which can generate the need for adjustments and institutional changes [4].

Although Bernauer [2] points out the difficulty of excluding water users at an acceptable cost, Martin [5] argues that the States make rational choices on the different ways to organize their interactions. Due to the interdependence generated by international basins, multilateralism is often the most appropriate way to arrange cooperation mechanisms for such resources. Multilateralism consists of three principles: (i) indivisibility - the behavior of the group forms a coherent whole; (ii) non-discrimination - all parties receive the same treatment; (iii) diffuse reciprocity - 'States do not rely on specific, quid-pro-quo exchanges, but on longer term assurances of balances in their relations' [5]. As a result, the benefits of cooperation become reasonably equivalent for all States over time. According to Martin [6], multilateralism is not absolutely necessary, but it may result in incentives for cooperation in specific cases, especially in the absence of a hegemon. In situations of great asymmetry, bilateral agreements based on immediate reciprocity are a feasible course of action. According to the author: 'asymmetries of interest or power do not always imply increased conflict of interest. Problems of distributing the gains of cooperation, for example, arise even when all actors have identical interests' [6]. Asymmetries reflect on different preferences and benefits, which help determine and facilitate the gains from trade, particularly through issue-linkages, and the concentration of capabilities in a smaller number of actors or a single actor can also facilitate cooperation because leadership is formed [6,7]. Considering time as a variable, the longer the expected duration of the cooperation (and consequent benefits), the more interesting it becomes for heterogeneous actors. The various forms of heterogeneity may be affected by political and social institutional arrangements, and the adequacy of such arrangements is the main facilitator of cooperation [8, 9]. However, cooperation does not arise solely from the need to overcome conflicts. It can also arise from the desire for joint exploitation of resources. In such cases, the creation of norms and procedures is facilitated by the fact that there is a common interest [8].

Considering the difficulty in excluding users from CPRs at an acceptable cost, we can assume that exogenous parameters, such as geography or technology, determine the number of actors involved [2, 10]. However, Snidal's findings [9] go beyond this assumption: the number of actors can sometimes be an endogenous issue. That is, membership determination is related to institutional rules and the expected results of cooperation: actors can choose to participate in the institutions or not; likewise, depending on the presented structure of costs, actors can be excluded from participation by others. Nevertheless, the possibility for such must respect Bernauer's hypothesis [2] that the costs of exclusion are acceptable compared to the potential benefits it generates. On this issue, Haftendorn [11] considers the asymmetries caused by the water flow - from upstream to downstream countries - and offers an interesting theoretical contribution, showing that cooperation can sometimes be a disadvantage, also indicating the requirements to reverse this situation: 'All running water conflicts 
are asymmetrical conflicts - (..) whereby there is a state or states that control a river's source or upper flow placing the lower lying riparian states at a disadvantage. As such a state or states would profit from this situation it would be in their favor to maintain the status quo and not to attempt to reach an understanding with the lower-lying riparians. (...) The dominant state relinquishes its hydrological advantage in return for specific rewards or political and material side payments. In this case, we assume that a crucial precondition for any solution of the conflict would be its linkage to other aspects of a bilateral or multilateral relationship' [11].

Cooperation may become a good alternative in situations involving countries with good bilateral relations, which have a tradition of solving problems in other areas through consensus. Because of such tradition, the conflict related to water resources would be treated separately, and the practice of cooperation in other arenas would increase the possibilities of agreement between the parties. This is also true for States with a high degree of interaction and interdependence where a cooperative strategy the optimal choice for the actors [8, 11]. Another hypothesis would be the interference of an outside arbitrator or negotiator, or even the presence of a more powerful State with interests in the conflict region, that would force the parties to reach an agreement. In the latter, the external interference changes the relative position of actors, making the choice of noncooperation an undesirable strategy, given the presented costs $[8,11]$. In addition to the 'previous institutional arrangements', in the first two cases, where cooperation in water resources management would be a small addition to an already cooperative relationship, the author [11] considers the possibility of interference from external actors - those who do not present themselves as appropriators of the CPR, but as parties that have interests and capabilities to influence cooperation arrangements.

From all previous considerations, there are three main conclusions. First, the exogenous parameters and the heterogeneity between actors determine institutional choices. Second, the geographical position of States in the river basin is important for the definition of costs and benefits of cooperation. Third, the resource appropriators are responsible for choosing the rules that will guide their interaction. This choice - crucial to the success of cooperation - is determined by a set of interests that are not necessarily related to the issue of shared water resources.

\section{Mekong river commission}

The Mekong is the largest river in Southeast Asia and the tenth river worldwide in terms of volume. The headwaters of the river lie in the densely populated Chinese province of Yunnan. From there, the Mekong runs through Laos, Burma, Thailand and Cambodia, and forms its delta in Vietnam before emptying into the South China Sea. The Lower Mekong Basin (Cambodia, Laos, Thailand and Vietnam) alone is home to more than 60 million people, and the river provides many of the population's basic needs, such as food, transportation, sanitation, electricity and irrigation [12]. As an example: 'Rice farming abetted 
by subsistence and semi-subsistence fishing is the dominant pattern of livelihood for the vast majority of the lower basin's inhabitants' [13].

The first large effort to promote river basin planning and international cooperation in the region occurred in 1957, with the creation of the Mekong Committee among the countries of the Lower Mekong Basin. There was great enthusiasm for cooperation on Mekong development, often referred to as 'The Mekong Spirit'. Throughout the following decades, the Committee was responsible for several programs and studies in the basin. However, the Cambodian civil war (1970-1975) and its aftermath resulted in that country's withdrawal from the Organization, which led the other States to establish the Interim Mekong Committee, in 1978.

In this scenario of instability, it is also relevant to consider the end of the Vietnam War, and with it, the end of most North-American funding for the Committee's projects, and also the exacerbation of economic disparities in the region: Thailand was going through an intense growth process, while the economies of neighboring nations remained stagnant. As a result, the Interim Mekong Committee followed through with modest studies, but was unable to achieve significant international cooperation, given that the major actor in the region, Thailand, was not willing to bear its costs $[13,14]$.

In 1991, after the end of the civil war, Cambodia requested to be re-admitted to the Committee. At that time, the country had several large-scale projects for the river, and a return to the Mekong Committee in its original format could mean a veto to such projects [12]. Thailand opposed Cambodia's request, and new negotiations, mediated by the United Nations Development Program (UNDP), resulted in the signature, in 1995, of the Agreement on the Cooperation for the Sustainable Development of the Mekong River Basin, which created the Mekong River Commission (MRC).

In the history of international cooperation in the Mekong Basin, the importance of external influence is evident. Considering that the presence of an external actor with interests in the region may alter the relative position of actors to favor or force an agreement [11], in the Mekong Committee, which came to existence during the Cold War, the presence of the United States was not only crucial for the initial agreement, but also for the cooperation to persevere in such endeavor. According to Osborne [15], not only was the USA the biggest source of funding for the region, but an American was nominated as the administrative head of the Committee as well. However, some of the 'Mekong Spirit' survived after the North-American withdrawal from the region. In 1995, once more, a new agreement was only made possible with the influence of the UNDP, which demonstrates the importance of external actors to reach a consensus in such matters.

The most significant change from the original 1957 Agreement to the 1995 version was regarding the need for consensual decision on major projects. In 1995, in compliance with Thailand's demands, the 'veto power' was abolished. The newly created MRC had China and Burma as dialog partners, and a Donor Consultative Group (donor countries and cooperating institutions) was instituted as part of the structure of the Organization. In the text of the Agreement, there is 
significant emphasis on the equitable use principle. There is also mention of the need for environmental protection and basin planning, but the document places greater emphasis in the tributaries and the mainstream separately, which, according to Fox and Sneddon [13], 'obfuscates the Mekong's existence as a multi-dimensional basin'. Not all projects need to be analyzed and authorized by MRC's Joint Committee (the Commission's main decision-making body) which, considering the conflictual political history of the region, might mean an attempt to reduce the interdependence to which they are all subject. It is plausible to assume that the States have opted for a form of cooperation that primarily avoids exposure to risk. The structure of the MRC is good enough to avoid conflict (the Organization is considered as model by some authors, due to the low incidence of conflict), but not as efficient in generating development from the shared use of basin resources - the main stated goal of the MRC.

One of the most internationally stressed principles for water governance is public participation (Dublin's second principle). Studies [2, 3, 9] show that, although the variables related to the geographical distribution of a CPR determine which actors share the resource, membership in a cooperation agreement is decided upon by its own members. The theory shows the difficulty in excluding users at an acceptable cost. However, the history of Southeast Asia is dominated by authoritarian political regimes and the participation of subnational actors is traditionally low. Thus, we have that the MRC formalizes relations among States. There has been significant international pressure, mainly from members of the Donor Consultative Group, for the expansion of public participation, but the results of such pressures have been feeble. A few reports have been released and the Organization has adopted a new concept of 'stakeholder' that includes non-state actors, but the fishery-related programs remain the only ones in which public participation has achieved some level of success [12]. Given the difficulty in expanding public participation even with external pressures, a likely conclusion is that, given the specific conditions of the region, it is less costly to exclude non-state actors than to include them.

According to Fox and Sneddon [13] the Commission was created to strengthen the relations between States while providing stimulus for regional development using the resources of the Mekong. However, the Organization oversimplifies the social and environmental structures of the basin, and it secludes both environmental balance and the basic needs of the riparian population from the main agenda. States' sovereignty does not reach equilibrium with the needs for integrated basin planning. The focus on hydroelectricity and transportation projects, along with the economic liberalization in the region, mostly stimulated by the Asian Development Bank, favors regional business groups and foreign investors [13, 17]. Environmental and social issues are not completely absent in the Commission's agenda. However, 'In seeing the Mekong basin as primarily a watercourse, the 1995 Agreement also enshrines the principle of equitable utilization as the central fulcrum of cooperative development. Equity as thus defined by the 1995 Agreement applies only to the sovereign states of the basin and elides considerations of socioecological justice at other levels and scales. (...), governance arrangements such as the Mekong 
Agreement, designed above all else to prevent inter-state conflicts, have little to say regarding water conflicts involving the livelihoods of basin residents' [13].

The biggest example of the States' recklessness regarding environmental and social damages is the case of the Chinese hydroelectricity and navigation projects in the Mekong. From 1996 to 2006, China has built and put into operation five dams and has projects for many more developments. Moreover, with the intention of increasing the navigability of the river, the country has implemented projects to deepen the flow of the river and eliminate sand banks, reefs and rapids - main breeding sites for the river's aquatic species. The environmental damage caused by the dams and alterations is extensive, and the consequences for the population may be even worse, due to their heavy dependence on the river's resources $[13,16]$.

The Mekong River Commission has succeeded in contributing to scientific research and in elaborating development plans, and it is also seen as a successful case with regard to conflict prevention. Nevertheless, the level of commitment to the international principles and guidelines for water resources management is very low, and such principles and guidelines are always adapted to the local decision-making structure. Considering the history of cooperation in the Mekong basin in the last decades, it is possible to identify two different scenarios: Mekong basin without Chinese presence, and Mekong basin with Chinese presence. Thailand, Laos, Cambodia and Vietnam are not homogeneous or symmetric States, but the Thai hegemony is only clearly established during the time of greater American financial support. The States' inability to coordinate actions makes the lack of trust among them evident. However, external incentives for cooperation - particularly from the US and the UN - have been great in the recent history of the Lower Mekong Basin. Given the limited amount of projects involving two or more States within the MRC, we can assume that most of the importance of the Commission is due to its role in bringing States closer and improving the exchange of information among them, which increases the level of trust and stability in the region. Thus, the issue-linkages between security and water resources development are evident, mostly before 1995 .

Cambodia's return to the Organization and the establishment of the MRC resulted in the abolishment of the 'veto power', and requirements for consultations with co-riparians were reduced as they reached an agreement that minimizes one State's interference in the action of others. So, there is little change in the ambitions of the cooperation: it may be hard to achieve significant joint action, but the MRC assures that States are well informed about the coriparians' actions and their usage of the shared resources.

The presence of China overturns this scenario. China is an external actor to the institutional arrangements and represents a clear hegemony in the region due to the capabilities it holds and to its upstream position in the basin. In a persuasion game, a clear hegemon is capable of persuading or coercing the other players, through compensations and threats [5]. Cooperation (as determined by the hegemon's preferences) represents the optimal payoff for the hegemon, and desertion represents the optimal payoff for the others. This is the case of China and the countries in the Lower basin. 


\section{UNECE water convention}

There is great diversity among the 56 member countries of the United Nations Economic Commission for Europe (UNECE). The availability of water resources in these countries is deeply uneven, and so are the related problems they face. Over $30 \%$ of the European population lives in countries that suffer from seasonal or permanent water stress. The increased frequency and intensity of floods and the dependence on overexploited aquifers is also a concern in some areas. Even though water scarcity and environmental damages due to water misuse are critical in some countries, irrigation and water distribution infrastructures still account for heavy losses of the resources. Water interdependence is also a relevant feature of the region [18]. According to the ECE: 'More than 150 major rivers and 50 large lakes in the UNECE region run along or straddle the border between two or more countries. Over 100 transboundary groundwater aquifers have been identified in Western and Central Europe, and more are expected to be identified in the rest of the region. Twenty European countries depend for more that $10 \%$ of their water resources on neighboring countries and five countries draw $75 \%$ of their resources from upstream countries' [18].

The UNECE Convention on the Protection and use of Transboundary Watercourses and International Lakes was signed in 1992, in Helsinki, and it was devised with the purposes of strengthening local, national and regional initiatives to protect and ensure the sustainable use of the water resources, and to promote cooperation though a basic set of rules. Nonetheless, there were previous treaties for many of the basins shared by UNECE Member States, and most countries were already subject to water usage regulations, especially those that are members of the European Union. Principles such as polluter-pays, equitable use, and the recommendation for integrated river basin management are present in the Convention. All signatories are required to prevent transboundary impacts and ecosystem damage, and are expected to consider the polluter-pays and the equitable use principles in water management decisions. As for the countries that share each of the river basins within the boundaries of the UNECE, they are expected to establish bilateral or multilateral organs to devise and monitor joint action plans and to facilitate the exchange of information and technology.

The principles and guidelines present in the Convention are set to guide future choices of the States. Major obligations are to be devised within the framework of the basin agreements - even if such agreements must respect the basic parameters established by the Convention. The Convention considers the State to be the main actor responsible for river basin management, and integrated river management is its principal recommendation. There is no major concern about non-state actors, given that the choices about their participation are to be made by the signatories once they devise and negotiate basin agreements. Since the adoption of the Convention, many basin agreements have been created, and the negotiation for some of them were made possible by the Convention's Secretariat. However, there are no enforcement mechanisms within the Convention, as such mechanisms are also to be devised in specific basin agreements. 
The examination of the roster of signatories of the Convention is key to analyzing the application of global principles and guidelines for water resources within the UNECE: 21 countries have not yet ratified the Convention. Some of them do not share river basins, and others have sufficient agreements on the issue. In spite of these and other cases, countries that suffer from chronic environmental and water management problems (mostly intense pollution, depletion of water resources caused by excessive withdrawals from irrigation systems, and lack of water and sewage treatment infrastructure) are the majority among the 21: such countries are located in the Balkans, Central Asia, and the Caucasus.

Most UNECE Member States are also members of other regional organizations and participate in numerous regional bilateral and multilateral treaties. Moreover, different basin agreements and European Union regulations preceded the adoption of the Water Convention. Thus, even before the rules of the Convention were negotiated a significant part of its signatories was constrained by some institutional arrangement when dealing with neighboring States and shared water resources. A high level of interaction and the presence of constrains from other institutional arrangements to which the States are subject may facilitate the cooperation among them [4, 11]. That is, in the case of a substantially interdependent group of States, the incentives for desertion in a singular situation are minimal. Thus, punitive rules are not essential to ensure obedience. In addition to this arguments, the number of non-signatories in less politically stable regions with a history of profound environmental degradation leads to the conclusion that UNECE Water Convention represents a small increase in the rules for transboundary water management in the region.

Previous institutional arrangements may be determinant in the structuring of cooperation. They act as intervening variables reducing the transaction costs and improving the capabilities to make credible commitments. However, for regions such as the Balkans, Central Asia and the Caucasus - or even the State of Israel, as an extreme case - the costs of accepting and adapting to the rules of the Convention are enormous, once we consider the resources and political effort it would demand.

All things considered, the acceptance of global principles and guidelines for water management in the territory of UNECE is a result of less recent process that is not directly related to the Water Convention. In regions where such a process does not exist the rules of the Convention have not been fully accepted. In spite of this fact, it is important to underline that the possibility of concerted actions between the Convention expert groups and the governments of nonsignatory countries decisively contributes to provide the means to incorporate the international principles and guidelines to their legal arrangements. Maybe this is the most relevant contribution of the Convention when it comes to its capacity to obtain a greater acceptance of such principles.

\section{Conclusion}

In the analysis of the MRC and the interaction among the four members it is pivotal to estimate to what extent the gains from cooperation outweigh the 
flexibility and autonomy of acting in the absence of institutional constrains. However, the presence of China as the region's hegemon unbalances the interactions: the negative effects of the Chinese hydroelectricity and transportation projects are felt in all four downstream States; nevertheless, they remain lenient due to the persuasion capabilities of the hegemon. Regarding UNECE, the member countries with higher level of national and international water management deficiencies, which makes cooperation more costly, are the ones that failed to ratify the Convention (China and Burma represent a similar case in Southeast Asia, but their distance from the MRC is mostly due to their political regimes). Thus, the main conclusion is that the Water Convention does not represent a major increase in the rules for transboundary water management in the countries that ratified it.

The cases of the ECE and the Mekong are distinct in their most fundamental characteristics. The UNECE Water Convention provides rules for a number of different river basins in 56 countries, while the Mekong River Commission provides the structure for the interactions of only 6 countries regarding the resources of a single river basin; in addition to that, the purpose of the Water Convention is to provide the basic framework for secondary basin treaties, while the MRC must deal with many different aspects of the Mekong basin - including the maintenance of regional stability. The level of commitment to the global principles and guidelines for water resources management is also distinct in each of the regions. Within the boundaries of the UNECE, the countries that ratified the Water Convention have high level of commitment to such principles and guidelines, regardless of enforcement mechanism. As for the countries in Southeast Asia, they show great resistance against the incorporation of these rules (to some extent, the abundance of water resources contributes to this).

Local variables (e.g. availability and distribution of water resources, conflicts of different natures, political history, interdependence, diffusion of environmental concerns) are of great importance to determine the State's capability and willingness to accept international recommendations, even if such recommendations are seen as global. In summary, with regards to understanding the incorporating of international principles and guidelines for water resources governance, it is possible to state that such principles and guidelines are incorporated only when they are adaptable or adequate to the local needs and political decision-making structure; in addition to that, regional agreements are based both on previous regionally accepted rules and in global recommendations, but the incorporation of subsequent rules to such agreements depend on their correspondence to the interest of the actors involved as well as their contribution to the better functioning of the sharing of water resources.

\section{References}

[1] Axelrod, R. \& Vig, N., The Global Environment - Institutions, Law and Policy, CQ Press: Washington DC, 1999. 
[2] Bernauer, T., Managing International Rivers (Chapter 6). Global Governance: Drawing Insights from the Environmental Experience, ed. Young, O., Cambridge: MIT Press, pp.155-195, 1997.

[3] Ostrom, E., Governing the Commons: an evolution of institutions for collective action, Cambridge: Cambridge University Press, 1990.

[4] Keohane, R. \& Ostrom, E., Introduction. Local Commons and Global Interdependence, eds. Keohane, R. \& Ostrom, E., pp. 1-26, 1995.

[5] Martin, L. Interests, Power and Multilateralism. International Organization, 46(2), pp. 765-792, 1992.

[6] Martin, L. Heterogeneity, linkage and common problems. (Chapter 4) Local Commons and Global Interdependence, eds. Keohane, R. \& Ostrom, E., pp. 71-91, 1995.

[7] Young, O., Problem of scale in human/environment relationships. (Chapter 4) Local Commons and Global Interdependence, eds. Keohane, R. \& Ostrom, E., pp. 27-45, 1995.

[8] Souza, M., Aguas Internacionais. Proc. of the $3^{\text {rd }}$ Conference of the Brazilian Association of Political Science, Niteroi: Federal Fluminense University, 2002.

[9] Snidal, D., The politics of scope: Endogenous actors, heterogeneity and institutions. (Chapter 3) Local Commons and Global Interdependence, eds. Keohane, R. \& Ostrom, E., pp. 47-70, 1995.

[10] Buck, S., The Global Commons; an introduction, Washington: Island, 1998.

[11] Haftendorn, H., Water and International Conflict. Proc. of the $40^{\text {th }}$ Annual Convention of the International Studies Association. Washington, 1999.

[12] Lauridsen, P., Transboundary Water Management in the Mekong: River of Controversy or River of Promise? Proc. of the International Conference Of the Danish Institute for International Studies, eds. Boesen, J. \& Ravnborg, H., Copenhagen, pp. 47-79,2004.

[13] Fox, C. \& Sneddon, C., Rethinking transboundary waters: A critical hydropolitics of the Mekong basin. Political Geography 25, pp. 181-202, 2006.

[14] Jacobs, J., The Mekong River Commission: transboundary water resources planning and regional security. The Geographical Journal 168(4), pp. 354364, 2002.

[15] Osborne, M., River at Risk: The Mekong and the Water Politics of China in the Southeast Asia. Sidney: Lowy Institute, 2004.

[16] Mekong River Commission, Public Participation in the Lower Mekong Basin: Working together for a better future. Viantiane, 2005.

[17] Hirsch, P., Globalization, regionalization and local voices: the Asian Development Bank and re-scaled politics of environment in the Mekong region. Singapore Journal of Tropical Geography 22, pp. 237-251, 2001.

[18] United Nations Economic Commission for Europe, What is it, why it matters? Geneva, 2004. 